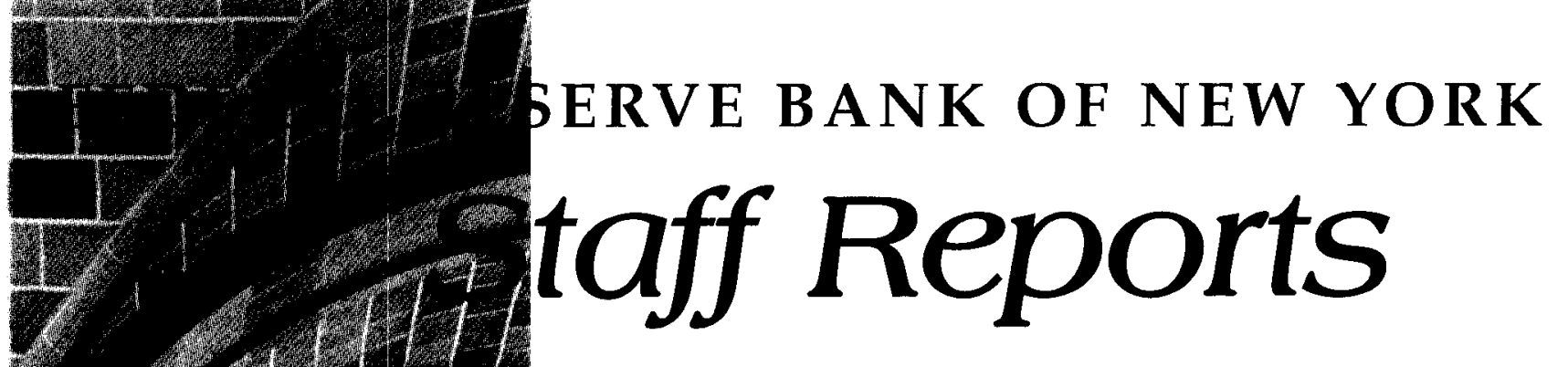

What Was the Market's View of U.K. Monetary Policy? Estimating Inflation Risk and Expected Inflation with Indexed Bonds

Eli M. Remolona

Michael R. Wickens

Frank F. Gong

Number 57, December 1998 


\title{
What Was the Market's View of UK Monetary Policy? Estimating Inflation Risk and Expected Inflation with Indexed Bonds
}

\author{
ELI M. REMOLONA \\ Federal Reserve Bank of New York \\ MiCHAEL R. WICKENS \\ University of York \\ FRANK F. GONG \\ Bank of America
}

\begin{abstract}
A measure of the credibility of monetary policy is the inflation risk premium in nominal yields. This will be time varying and can be estimated by combining the information in the nominal term structure with that in the real term structure. We estimate these risk premia using a generalized $\mathrm{CIR}$ affine-yield model, with one factor driving the real term structure of monthly observations on two-year, five-year and ten-year UK index-linked debt and two factors driving the term structure of the corresponding nominal yields. Our estimates show that the inflation risk premium contributes on average about 100 basis points to nominal yields. Since the exit from the ERM this has fallen to 70 basis points, showing greater policy credibility. The inflation risk premium provides a correction to the break-even method of forecasting inflation and produces an unbiased forecast.
\end{abstract}

JEL codes: E31, E43, E62, G12

Keywords: Inflation risk, expected inflation, indexed bonds, affine yields and monetary policy

Acknowledgements: the authors would like to thank Nicola Anderson, Robert Bliss, Roger Brown and the Bank of England for their comments.

Corresponding author: Eli M. Remolona, Capital Markets Function, Federal Reserve Bank of New York, New York, NY 10045; tel.: (212) 720 6328; fax: (212) 720 1582; E-mail: eli.remolona@ @y.frb.org. 


\section{What Was the Market's View of UK Monetary Policy? \\ Estimating Inflation Risk and Expected Inflation with Indexed Bonds}

\section{Introduction}

The inflation risk premium embodied in the term structure of interest rates contains information that is potentially highly useful. It provides a measure of the credibility of monetary policy, it can be used to derive an improved estimate of the inflation expectations implicit in the term structure, and it shows the cost of issuing nominal rather than index-linked debt. The problem is that, to date, estimates have only been obtained of the nominal risk premium, or of the real risk premium which provides information about the market's view of uncertainty about the real economy.

In this paper we show how to obtain separate estimates of the inflation and real risk premia by simultaneously fitting a one-factor model of the real term structure and a two-factor model of the nominal term structure to data on UK index-linked and nominal debt over the period July 1982 to July 1997. Both models are generalized Cox-Ingersoll-Ross (CIR) affine factor pricing rnodels. Estimates of the one-period inflation and real risk premia in holding returns, and the $n$-period inflation and real premia in yields are then extracted. Their behaviour is examined during key episodes in the UK economy over this period. We are interested, for example, in the effect of sterling's membership in the ERM and its abrupt departure in September 1992. We find that accompanying these events there are changes in both the inflation and the real risk premia. We estimate that the average inflation risk premium in two-year nominal yields over the whole sample is about 100 basis points, and that this fell to about 70 basis points after sterling left the ERM. This is also a measure of the cost of issuing nominal rather than index-linked debt, and the size of the correction needed to the estimate of inflation expectations obtained from the break- 
even method (i.e. the difference between nominal and indexed yields on matched zero-coupon bonds).

The U.K. government has been issuing inflation-indexed gilts since 1981. Index-linked bonds differ from real bonds due to a lag in the timing of the indexation of both the final payment and the coupons. In the UK this is eight months. More recently other countries have begun to issue index-linked debt, such as the US, where the lag is three months, Australia, Hungary, Israel, Sweden and, shortly, France. The main attraction of index-linked bonds is that they reduce the cost of borrowing by eliminating the inflation component of the risk premium. It is sometimes claimed that markets are reluctant to hold index-linked debt because the real retums are too low. If true, this raises the intriguing question of whether markets are treating the inflation risk premium as part of the real retum. With the increase in indexed debt issues, interest in analysing the inflation and real term structure can be expected to increase in the future.

Earlier attempts to measure inflationary ex.pectations from nominal bond yields by Fama (1990) and Mishkin (1990) found that the U.S. yield curve reflected expectations of inflation, especially at long maturities. Engsted (1995) provides similar evidence for other countries. At the same time, they all find that variation in real rates or term premia obscures those expectations. Consequently, Frankel and Lown (1994) extract inflationary expectations from the yield curve by letting the real interest rate vary in the short run but revert to a mean in the long run. Steeley (1997) uses a two-factor model to decompose the forward premium in U.K. nominal gilts into time-varying risk premia. Earlier studies with U.S. data confirm the significance of time-varying term premia in bond returns (e.g., Shiller, Campbell, and Schoenholtz, 1983; Fama, 1984; and Keim and Stambaugh, 1986). Engle, Lilien and Robins (1987) fit an ARCH-M model to interest rate data and find a highly significant time-varyingr risk premium. More recently, Tzavalis and Wickens $(1997,1998)$ find that allowing for risk premia that vary over time can greatly help to reconcile the rational expectations hypothesis with the data. None of these studies distinguish 
between the real and the inflation risk premium, a distinction important for indexed bonds because the expected reduction in the issuer's borrowing cost comes only from eliminating the inflation risk premium.

In previous work on indexed-linked bonds, the yields have been used to estimate the real term structure (Brown and Schaefer, 1994; 1996). Differences between the yields on nominal and indexed bonds have been used to extract estimates of inflation rates expected by market participants (e.g., Arak and Kreicher, 1985; Deacon and Derry, 1994; and Barr and Campbell, 1995). The Bank of England has recently relied on such estimates to infer changes in inflationary expectations (King, 1995). The presence of an indexation lag implies that the inflation risk cannot be entirely eliminated (see Brown and Schaefer, 1994, for example, for further details). This can be particularly important around the time of maturity. Levin and Copeland (1993) use the indexation lag to extract estimates of the inflation risk premium from yields on just indexlinked gilts. Their approach, however, requires the assumption of a flat real term structure and leads to negative estimates of the risk premium. Evans (1998) compares yields on U.K. nominal and index-linked gilts and finds that the indexation ling is not important but a time-varying inflation risk premium is. Barr and Campbell (1997) point out that estimating such a risk premium requires an equilibrium model.

The models of the nominal and real term stnictures that we employ involve two unobservable factors, one associated with the real return and the other with inflation. The onefactor model serves to identify the real rate process and its risk premium, and the two-factor model combines the inflation and the real factors to describe nominal yields. Together the two models allow us to extract the inflation process and the inflation risk premium. The factor models provide arbitrage conditions that let us simultaneously exploit information in yield movements across the nominal and real term structures. In the models, heteroskedastic shocks to 
the factors are possible sources of risks priced by the market, permitting both inflation risk premia and real term premia to vary over time.

To estimate the models simultaneously, wi: apply a Kalman filter to monthly data on three rominal and three index-linked zero-coupon bond yields for U.K. The indexed yields serve to identify the perceived real rate process, allowing us to extract the perceived inflation process from the nominal yields. The estimation procedurs allows us to exploit the conditional density of bond yields without requiring special assumptions about measurement error. The model's arbitrage conditions serve as overidentifying restrictions. Steeley (1996) finds that a two-factor model explains the magnitude of the forward premium in nominal U.K. gilts from 1992 to 1996. We limit ourselves to fitting the model to two-year, five-year and ten-year yields. Working with U.S. data, Gong and Remolona (1996) suggest that a two-factor model works reasonably well in this range of maturities, while Dai and Singleton (1998) show that at least three factors are required to fit the whole term structure. We estimate our model for three monetary regimes, July 1982 to September 1990, October 1990 to August 1992, and September 1992 to July 1997.

The paper is organized as follows: Section 2 presents the two-factor equilibrium model. Section 3 explains the econometric methodology. Section 4 discusses the results, reports our estimates of the inflation and real risk premia. It also presents our corrected estimates of inflation expectations over a two-year and one-year horizon, and tests whether they provide an unbiased forecast of future inflation. Section 5 summarizes our findings. 


\section{One-factor and two-factor affine-yield models}

\subsection{Theoretical background}

Theoretical work by Vasicek (1977) and Cox, Ingersoll, and Ross (1985) showed how the term structure at a moment in time would reflect regularities in interest rate movements over time. In particular, long maturity yields would depend on mean reversion in the short-term interest rate and on the risk associated with the volatility of that rate. The basic results relied on an arbitrage condition imposed on continuous-time processes. Sun (1992), Backus and Zin (1994), and Campbell, Lo, and MacKinlay (1994, hereafter CLM) derive the same results for discrete-time models by means of a stochastic discount rate process called the pricing kernel. Applying the same pricing kernel to price bonds of different maturities effectively imposes an equilibrium that admits no arbitrage. Specifying a discrete-time process from the outset avoids the pitfalls of estimating a continuous-time process with discrete-tine data. ${ }^{1}$ We use a generalization of the CIR model proposed by Pearson and Sun (1994). This is in the affine class of models but provides additional flexibility in the conditional variance process.

\subsection{Pricing indexed bonds: A one-factor model}

The prices of indexed bonds will depend on at single factor representing the expectation of real return. Using the CIR model, Brown and Schsefer (1994) have estimated such a model with data on yields on U.K. index-linked gilts. We s'art with an arbitrage condition common to intertemporal asset pricing models. ${ }^{2}$ The price of a zero-coupon $n$-period indexed bond can be written as

\footnotetext{
1 As Ait-Sahalia (1996) points out, the approximation of a cont nuous-time process by discretization methods is difficult to justify for monthly, weekly, or daily observations. The approximation is exact only in special cases (see Wong, 1964).

2 Singleton (1990) surveys such models and their empirical performance.
} 


$$
P_{n t}^{R}=E_{t}\left[M_{t+1}^{R} P_{n-1, t+1}^{R}\right]
$$

where $M_{t+1}^{R}$ is the stochastic discount factor and $P_{n-1, t+1}^{R}$ is the price of the same bond a period later. We can solve (1) forward to get $P_{n t}^{R}=E_{t}\left[M_{t+1}^{R} \ldots M_{t+n}^{R}\right]$, which shows that we can model $P_{n t}^{R}$ by modeling the stochastic process for $M_{t+1}^{R}$. We assume that $M_{t+1}^{R}$ is conditionally lognormal, so that we can take logs of (1) and write it as

$$
p_{n t}^{R}=E_{t}\left(m_{t+1}^{R}+p_{n-1, t+1}^{R}\right)+\frac{1}{2} \operatorname{Var}_{t}\left(m_{t+1}^{R}+p_{n-1, t+1}^{R}\right)
$$

where lower-case letters denote logarithms.

We assume that the pricing kernel for indexed bonds is driven by a single factor representing expected real returns:

$$
-m_{t+1}^{R}=x_{1 t}+w_{t+1}^{R}
$$

where $x_{1 t}$ is the single factor and $w_{t+1}^{R}$ is a shock related to real risk. The factor itself is assumed to follow a generalized CIR process, i.e. it is an AR(1) process with a heteroskedastic shock based on the square-root process:

$$
x_{1, t+1}=\left(1-\phi_{1}\right) \mu_{1}+\phi_{1} x_{1 t}+\left(1+\beta_{1} x_{1 t}\right)^{1 / 2} \sigma_{1} u_{i, t+1}
$$

where $\left(1-\phi_{1}\right)$ is the factor's rate of mean reversion, $\mu_{1}$ is the long-run mean to which the factor reverts, $\sigma_{1}$ is the volatility of the shock $u_{1, t+1}$ which is an iid $(0,1)$ process. The shock to the factor is itself the source of the shock to the stochastic discount factor: 


$$
w_{t+1}^{R}=\lambda_{1}\left(1+\beta_{1} x_{1 t}\right)^{1 / 2} \sigma_{1} u_{1, t+1},
$$

where $\lambda_{1}$ is expected to be negative. As $\sigma_{1} \rightarrow 0$ such that $\sigma_{1}^{2} \beta_{1} \rightarrow \eta_{1}^{2}$ this model becomes the discrete-time specification of the CIR (1985) one-factor square-root model with volatility $\eta_{1}$, the model applied by Brown and Schaefer (1994) to short-term yields on U.K. index-linked gilts. In this case $\lambda_{1}$ would be the price of real risk. It may be noted that although CIR require that the factor process (4) is stationary, this is not necessary for our results. Because we are evaluating conditional, and not unconditional expectations, even if $\phi_{1}=1$, our results are unchanged.

In general, we can write the price of an $n$-period indexed bond as a linear function of the factor:

$$
-p_{n t}^{R}=A_{n}^{R}+B_{1 n}^{R} x_{1 t}
$$

where $A_{n}^{R}$ represents the pull of the factor to its mein and the factor loading $B_{1 n}^{R}$ has the property of a duration. Since yields on indexed bonds are given by $r_{n t}=-p_{n t}^{R} / n$, these yields are also linear in the factor. In other words, yields are affine.

The importance of the model lies in the arbitrage conditions it imposes on yield movements across the term structure. Substituting (6) into (2), it can be shown that $A_{n}^{R}$ and $B_{1 n}^{R}$ satisfy the recursive equations

$$
\begin{aligned}
& A_{n}^{R}=A_{n-1}^{R}+\left(1-\phi_{1}\right) \mu_{1} B_{1, n-1}^{R}-\frac{1}{2}\left(\lambda_{1}+B_{1, n-1}^{R}\right)^{2} \sigma_{1}^{2} \\
& B_{1 n}^{R}=1+\phi_{1} B_{1, n-1}^{R}-\frac{1}{2}\left(\lambda_{1}+B_{1, n-1}^{R}\right)^{2} \beta_{1} \sigma_{1}^{2}
\end{aligned} .
$$


These represent arbitrage conditions to be satisfied by yields on indexed bonds with different maturities.

At maturity bonds trade at par implying that $p_{0 t}^{R}=0$ and hence $A_{0}^{R}=B_{10}^{R}=0$. Thus

$$
-p_{1 t}^{R}=r_{1 t}=x_{1 t}-\frac{1}{2} \lambda_{1}^{2} \sigma_{1}^{2}\left(1+\beta_{1} x_{1 t}\right)
$$

where $r_{1 t}$ is the one-period indexed yield or the real short rate. Note that this yield is linear in the factor $x_{1 t}$. Linearity in a single AR(1) factor means indexed yields are also AR(1).

We can derive conditional volatilities by taking the conditional variance of $r_{n, t+1}=\left(A_{n}^{R}+B_{1 n}^{R} x_{1, t+1}\right) / n:$

$$
\operatorname{Var}_{t}\left(r_{n, t+1}\right)=\frac{1}{n^{2}}\left(B_{1 n}^{R}\right)^{2} \sigma_{1}^{2}\left(1+\beta_{1} x_{1 t}\right)
$$

Hence, conditional volatilities follow ARCH processes.

The real risk premium for one period excess holding returns is obtained by taking the expected excess return on an $n$-period indexed bond:

$$
E_{t} p_{n-1, t+1}^{R}-p_{n t}^{R}-r_{1 t}=-\left[\lambda_{1} B_{1, n-1}^{R}+\frac{1}{2}\left(B_{1, n-1}^{R}\right)^{2}\right]\left[\left(1+\beta_{1} x_{1 t}\right) \sigma_{1}^{2}\right]
$$

This can also be written as

$$
E_{t} p_{n-1, t+1}^{R}-p_{n t}^{R}-r_{1 t}=-\left[\left(\lambda_{1}+\frac{1}{2} B_{1, n-1}^{R}\right)\left(1+\beta_{1} x_{1 t}\right)^{1 / 2} \sigma_{1}\right]\left[B_{1, n-1}^{R}\left(1+\beta_{1} x_{1 t}\right)^{1 / 2} \sigma_{1}\right]
$$


when the first term in square brackets on the right-hand side has the interpretation of the market price of risk. ${ }^{3}$ The terms in this square bracket not involving $\lambda_{1}$ represent the effects of Jensen's inequality.

\subsection{Pricing nominal bonds: A two-factor model}

The pricing kemel for nominal bonds is driven by expectations of both real returns and inflation. To price nominal bonds, we specify the conditional expectation of the negative of the $\log$ stochastic discount factor as the sum of a real and an inflation discount factor

$$
-m_{t+1}^{N}=-m_{t+1}^{R}+x_{2 t}+w_{t+1}^{N}
$$

where $m_{t+1}^{R}$ is the real stochastic discount factor specified in (3) and the remaining terms define the inflation discount factor with $x_{2 t}$ the expectation of inflation, and $w_{t+1}^{N}$ a shock related to inflation risk. It is assumed that the second factor follows a generalized CIR process like (4)

$$
x_{2, t+1}=\left(1-\phi_{2}\right) \mu_{2}+\phi_{2} x_{2 t}+\left(1+\beta_{2} x_{2 t}\right)^{1 / 2} \sigma_{2} u_{2, t+1}
$$

where $\left(1-\phi_{2}\right)$ is the rate of mean reversion, $\mu_{2}$ is the long-run mean, $\sigma_{2}$ is volatility and $u_{2, t+1}$ is an iid $(0,1)$ assumed to be uncorrelated with $u_{1, t+1}$. The additional shock to the $\log$ stochastic discount factor is

$$
w_{1+1}^{N}=\lambda_{2}\left(1+\beta_{2} x_{2 t}\right)^{1 / 2} \sigma_{2} u_{2, r+1}
$$

\footnotetext{
${ }^{3}$ This expression is more familiar in continuous time. In the pricing equation $d P / P=(r+\lambda \beta) d t+\beta d z$, where $d z$ is a Wiener process, $\lambda$ is known as the market price of risk and $\beta$ as the quantity of risk.
} 
where $\lambda_{2}$ is expected to be negative, and represents the market price of inflation risk when $\beta_{2}=0$

To derive the price of an $n$-period nominal bond, again we assume that the stochastic discount factor is conditionally lognormal. The log price of a nominal bond can then be written as

$$
p_{n t}^{N}=E_{l}\left(m_{t+1}^{N}+p_{n-1, t+1}^{N}\right)+\frac{1}{2} \operatorname{Var}_{t}\left(m_{t+1}^{N}+p_{n-1, t+1}^{N}\right)
$$

We can now write the log price of an $n$-period nominal bond as linear functions of two factors:

$$
-p_{n t}^{N}=A_{n}^{N}+B_{1 n}^{N} x_{1 t}+B_{2 n}^{N} x_{2 t}
$$

with yields given by $y_{n t}=-p_{n t}^{N} / n$. The coefficients $B_{1 n}^{N}$ and $B_{2 n}^{N}$ are factor loadings. The coefficient $A_{n}^{N}$ represents the pull of the factors to their respective means. These coefficients are derived from the recursive equations

$$
\begin{aligned}
& A_{n}^{N}=A_{n-1}^{N}+\left(1-\phi_{1}\right) \mu_{1} B_{1, n-1}^{N}+\left(1-\phi_{2}\right) \mu_{2} B_{2, n-1}^{N}-\frac{1}{2}\left(\lambda_{1}+B_{1, n-1}^{N}\right)^{2} \sigma_{1}^{2}-\frac{1}{2}\left(\lambda_{2}+B_{2, n-1}^{N}\right)^{2} \sigma_{2}^{2} \\
& B_{1 n}^{N}=1+\phi_{1} B_{1, n-1}^{N}-\frac{1}{2}\left(\lambda_{1}+B_{1, n-1}^{N}\right)^{2} \beta_{1} \sigma_{1}^{2} \\
& B_{2 n}^{N}=1+\phi_{2} B_{2, n-1}^{N}-\frac{1}{2}\left(\lambda_{2}+B_{2, n-1}^{N}\right)^{2} \beta_{2} \sigma_{2}^{2}
\end{aligned}
$$

Applying the normalization $p_{0 t}^{N}=0$ to fix at par the price of a nominal bond at maturity, we derive the nominal short rate as 


$$
\begin{aligned}
& y_{1 t}=-p_{t "}^{N}=-E_{t}\left(m_{t+1}^{N}\right)-\frac{1}{2} \operatorname{Var}_{t}\left(m_{t+1}^{N}\right) \\
& =x_{1 t}-\frac{1}{2} \lambda_{1}^{2} \sigma_{1}^{2}\left(1+\beta_{1} x_{1 t}\right)+x_{2 t}-\frac{1}{2} \lambda_{2}^{2} \sigma_{2}^{2}\left(1+\beta_{2} x_{2 t}\right)
\end{aligned}
$$

which is linear in the two factors.

It may be noted that $B_{1 n}^{N}=B_{1 n}^{R}$ which rules out arbitrage opportunities between nominal and indexed bonds. Linearity in the two $\operatorname{AR}(1)$ factors results in yields that are $\operatorname{ARMA}(2,1)$ processes and conditional yield volatilities that are GARCH processes. They also imply that the $\log$ price of a nominal bond is the sum the log price of a real bond and an inflation component. Moreover, it can be shown that the nominal risk premium is the sum of the real and the inflation risk premia.

The nominal risk premium on one period excess holding returns for an $n$-period nominal bond is

$$
\begin{aligned}
E_{t}\left(p_{n-1, t+1}^{N}\right)-p_{n t}^{N}-y_{1 t} & =-\left[\lambda_{1} B_{1, n-1}^{R}+\frac{1}{2}\left(B_{1, n-1}^{R}\right)^{2}\right] \sigma_{1}^{2}\left(1+\beta_{1} x_{1 t}\right) \\
& -\left[\lambda_{2} B_{2, n-1}^{N}+\frac{1}{2}\left(B_{2, n-1}^{N}\right)^{2}\right] \sigma_{2}^{2}\left(1+\beta_{2} x_{2 t}\right)
\end{aligned}
$$

This can be written as

$$
\begin{aligned}
E_{t}\left(p_{n-1, t+1}^{N}\right)-p_{n t}^{N}-y_{1 t} & =-\left[\left(\lambda_{1}+\frac{1}{2} B_{1, n-1}^{R}\right)\left(1+\beta_{1} x_{1 t}\right)^{1 / 2} \sigma_{1}\right]\left[B_{1, n-1}^{R}\left(1+\beta_{1} x_{1 t}\right)^{1 / 2} \sigma_{1}\right] \\
& -\left[\left(\lambda_{2}+\frac{1}{2} B_{2, n-1}^{N}\right)\left(1+\beta_{2} x_{2 t}\right)^{1 / 2} \sigma_{2}\right]\left[B_{2, n-1}^{N}\left(1+\beta_{2} x_{2 t}\right)^{1 / 2} \sigma_{2}\right]
\end{aligned}
$$

where the term in the third set of square brackets on the right-hand side is the market price of inflation risk. 


\subsection{Expected inflation and the cost of inflation}

Deacon and Derry (1994) identify three methods of deriving inflation expectations by combining information from the real and nominal yield curves. The simplest is to subtract the yield on indexed-linked stock from the nominal yield at matching maturities. This gives an estimate of average expected inflation until the bonds mature. Although it has the advantage over using only the nominal yield curve of eliminating the need to assume a real interest rate, this approach still has several weaknesses. One is that it takes no account of the different duration of the indexed-linked and nominal bonds arising from different coupons. The "break-even" method addresses this point by using the yields on the corresponding implied zero-coupon bonds. A further limitation of both methods is that few matching maturities are available due to the small number of index-linked bonds in existence. To overcome this, Deacon and Derry fit cubicsplines to the two yield curves; yields for any maturity may then be interpolated. Even after these improvements, as Deacon and Derry acknowledge, there is still a major problem with these three approaches as no account has been taken of the inflation risk premium contained in nominal yields.

The correct measure of the inflation expectations embedded in the nominal yield of an $n$ period bond is the difference between the nominal and indexed yields on n-period zero-coupon bonds less the inflation risk premium which is the expected average of the one period inflation risk premia until the bond matures. If the real and nominal one period risk premia defined by equations (10) and (18) are denoted $\varphi_{n, t}^{R}$ and $\varphi_{n, t}^{N}$ respectively, then the indexed and nominal yields on n-period bonds can be obtained by averaging these equations from period $t$ to $t+n$ to give

$$
r_{n t}=\frac{1}{n} E_{t} \sum_{i=0}^{n-1} r_{1, t+i}+\frac{1}{n} E_{t} \sum_{i=0}^{n-1} \varphi_{1, t+i}^{R}
$$


and

$$
y_{n t}=\frac{1}{n} E_{t} \sum_{i=0}^{n-1} y_{1, t+i}+\frac{1}{n} E_{t} \sum_{i=0}^{n-1} \varphi_{1, t+i}^{N}
$$

Equations (19) and (20) express the standard result that the n-period yield is the expected average of future one period rates and the risk premia on one period retums.

Due to the affine structure of yields, the one period inflation risk premium is $\varphi_{n, t}^{\pi}=\varphi_{1, t}^{N}-\varphi_{1, t}^{R}$ and the inflation component of the risk premium of an $n$-period yield is $\frac{1}{n} E_{i} \sum_{i=0}^{n-1} \varphi_{1, t+i}^{n}=\frac{1}{n} E_{i} \sum_{i=0}^{n-1} \varphi_{1,+i}^{N}-\frac{1}{n} E_{t} \sum_{i=0}^{n-1} \varphi_{1, t+i}^{R}$. This is a measure of the cost of inflation uncertainty that is embodied in nominal yields. Denoting expected inflation in period $t$ as $E_{1} \pi_{t+1}$ and using the definition $r_{i t}=y_{i t}-E \pi_{i+1}$, expected average inflation from $t$ to $t+n$ is obtained from (19) and (20) as

$$
\frac{1}{n} E_{\mathrm{r}} \sum_{i=0}^{n-1} \pi_{1, t+i}=y_{n t}-r_{n t}-\frac{1}{n} E_{i} \sum_{i=0}^{n-1} \varphi_{1, t+i}^{\pi}
$$

where, from (18), the expectations of the future one period inflation risk premia are evaluated using

$$
E_{t} \varphi_{i, t+i}^{\pi}=-\left[\lambda_{2} B_{2, n-1}^{N}+\frac{1}{2}\left(B_{2, n-1}^{N}\right)^{2}\right] \sigma_{2}^{2}\left(1+\beta_{2} E_{t} x_{2, t+i}\right)
$$

and, from (12),

$$
E_{t} x_{2, t+i}=\left(1-\phi_{2}^{i}\right) \mu_{2}+\phi_{2}^{i} x_{2 t}
$$


If the observed yields in (21) are replaced by the affine factor models (7) and (16), it is possible to determine the expected average inflation for any length of time, and not just the time horizons of observed maturities. We shall exploit this later.

It is possible to derive a corresponding expression to (21) for the expected average real return, namely,

$$
\frac{1}{n} E_{t} \sum_{i=0}^{n-1} r_{1, t+i}=r_{n t}-\frac{1}{n} E_{t} \sum_{i=0}^{n-1} \varphi_{1, t+i}^{R}
$$

where the expected one-period real risk premium is

$$
E_{t} \varphi_{i, r+i}^{R}=-\left[\lambda_{1} B_{1, n-1}^{R}+\frac{1}{2}\left(B_{1, n-1}^{R}\right)^{2}\right] \sigma_{1}^{2}\left(1+\beta_{1} E_{t} x_{1, r+i}\right)
$$

and

$$
E_{t} x_{1, t+i}=\left(1-\phi_{1}^{i}\right) \mu_{1}+\phi_{1}^{i} x_{1 t}
$$

\section{Econometric methodology}

Due to the presence of the two unobservable factors, the model lends itself to the use of the Kalman filter. The conditional density of the observable variables can be used to provide maximum likelihood estimates from which the unobservable factors can be extracted. We apply the Kalman filter to the yields on 2-year, 5-year and 10-year U.K. index-linked and nominal gilts. Estimates of the yields of any other maturities and their real and inflation risk premia can be derived from these. The yields on indexed bonds are used to identify the perceived real rate process, which can then be combined with the yields on nominal bonds to extract the perceived 
inflation process. The model's arbitrage conditions can be used to provide over-identifying crossequation restrictions.

Other maximum likelihood procedures also allow the use of conditional moments to estimate term structure models, but these procedures require special assumptions about measurement errors. Chen and Scott (1993) estimate a one-factor model, a two-factor model, and a three-factor model by maximizing a likelihood based on the factors' conditional moments. To derive the factors, however, their procedure requires the arbitrary assumption of zero measurement error for as many yields as they have factors. Pearson and Sun (1994) also exploit the factors' conditional density in estimating a two-factor CIR (1985) model. They derive the factors by using two yields at a time and assume no measurement enror for either yield. The Kalman filter provides a way to exploit the conditional moments of bond yields while allowing measurement errors for these variables. The measurement errors may arise from bond mispricing, smoothing errors in fitting the yield curve, or poor model specification. Jegadeesh and Pennacchi (1996) and Gong and Remolona (1997) have implemented the Kalman filter procedure for two-factor models.

The model can be written in linear state-space form with six measurement equations and two transition equations. The measurement equations are obtained by adding measurement errors to the affine pricing functions for real and nominal bonds, equations (7) and (16). The resulting six equations are

$$
\left[\begin{array}{c}
r_{24, t} \\
r_{60, t} \\
r_{120, t} \\
y_{24, t} \\
y_{60, t} \\
y_{120, t}
\end{array}\right]=\left[\begin{array}{c}
a_{24}^{R} \\
a_{60}^{R} \\
a_{120}^{R} \\
a_{24}^{N} \\
a_{, 60}^{N} \\
a_{120}^{N}
\end{array}\right]+\left[\begin{array}{cc}
b_{1,24} & 0 \\
b_{1,60} & 0 \\
b_{1,120} & 0 \\
b_{1,24} & b_{2,24} \\
b_{1,60} & b_{2,60} \\
b_{1,120} & b_{2,120}
\end{array}\right]\left[\begin{array}{l}
x_{1 t} \\
x_{2 t}
\end{array}\right]+\left[\begin{array}{c}
v_{24, t}^{R} \\
v_{60, t}^{R} \\
v_{120, t}^{R} \\
v_{24, t}^{N} \\
N \\
v_{60, t} \\
v_{120, t}^{N}
\end{array}\right]
$$


where $r_{i, t}$ and $y_{i, t}$ are yields on index-linked and nominal gilts for maturities $i=24,60$, and

120 months. The coefficients are given by $a_{k}^{J}=A_{k}^{J} / k, b_{1 k}=B_{1 k}^{R} / k=B_{1 k}^{N} / k$, and $b_{2 k}=B_{2 k}^{N} / k$ for $J=R, N$ and $k=24,60,120$. The $v_{k l}^{J}$ 's are measurement errors distributed with zero mean and standard deviations $\omega_{k}^{J}$. Note that while we use yields on index-linked gilts to identify the perceived real rate process, in estimating the process we also use information from yields on nominal gilts. ${ }^{4}$

The transition equations for the two factors consist of equations (4) and (12)

$$
\left[\begin{array}{l}
x_{1 t} \\
x_{2 t}
\end{array}\right]=\left[\begin{array}{l}
\left(1-\phi_{1}\right) \mu_{1} \\
\left(1-\phi_{2}\right) \mu_{2}
\end{array}\right]+\left[\begin{array}{cc}
\phi_{1} & 0 \\
0 & \phi_{2}
\end{array}\right]\left[\begin{array}{l}
x_{1, t-1} \\
x_{2, t-1}
\end{array}\right]+\left[\begin{array}{c}
\left(1+\beta_{1} x_{1, t-1}\right)^{1 / 2} \sigma_{1} u_{1, t} \\
\left(1+\beta_{2} x_{2, t-1}\right)^{1 / 2} \sigma_{2} u_{2, t}
\end{array}\right],
$$

where the shocks $u_{1 t}$ and $u_{2 t}$ are distributed niid $[0,1]$.

In standard linear state-space models, no restrictions link the measurement and transition equations. In our model, however, the arbitrage conditions serve as over-identifying restrictions that link the coefficients of the measurement equations (21) to those of the transition equations (28). These restrictions are given by (8) and (17) with initial values set by (6) and (15) and to be satisfied by ten parameters: the persistence parameters $\phi_{1}$ and $\phi_{2}$, the long-run means $\mu_{1}$ and $\mu_{2}$, the risk parameters $\lambda_{1}$ and $\lambda_{2}$, the betas $\beta_{1}$ and $\beta_{2}$, and the volatilities $\sigma_{1}$ and $\sigma_{2}$. After incorporating the restrictions into the measurement equations, the model is estimated by maximum likelihood using the Kalman filter's conditional updating procedure. Since the

\footnotetext{
${ }^{4}$ We shall assume that the presence of measurement error does not affect the formulae derived above. It might be argued, however, that if investors are aware of the measurement errors, then they might be expected to take them into accourt when pricing bonds as they would alter the affine pricing equation.
} 
measurement errors prevent us from solving the factors directly from the measurement equations, the likelihood function is based on the conditional density of the yields rather than the factors.

\section{Results}

\subsection{Data and summary statistics}

We use estimated monthly yields from July 1982 to July $1997 .^{5}$ Neither zero-coupon yields nor yields for the full term structure are directly observable; for example, at any point in time there are only a small number of indexed gilts in existence. These data are constructed by fitting a cubic spline function to observed yields, interpolating intermediate points on the yield curve and converting to zero-coupon yields. ${ }^{6}$

Arguably, during this time there were three different monetary regimes, each reflecting sterling's position within the ERM. The period from July 1982 to September 1990 was prior to sterling joining the ERM; from October 1990 to August 1992 sterling was a full member of the ERM, but left in September 1992. The post-ERM period coincides closely with an inflationtargetting regime which started in October 1992. It is possible that the real rate and inflation processes perceived by market participants, and the prices they attached to real rate and inflation risk differed for the three regimes. To examine this possibility we estimate the model for the whole period and for the three sub-periods.

Fig. 1 displays the real and nominal yields for two-year, five-year and ten-year gilts for the complete data period and Table 1 provides summary statistics. Several features are worth noting. There is a steady rise in nominal yields in the two years prior to sterling joining the ERM,

\footnotetext{
${ }^{5}$ We are very grateful to the Bank of England for supplying the data.

${ }^{6}$ See Deacon and Derry (1994) for more details of the construction of the data.
} 
followed by a decline whilst sterling is in the ERM, and then a sharp fall on sterling's exit with another rise in 1994. As a result, 2-year are more volatile than 5-year and 10-year nominal yields throughout the data period and showed greatest volatility in the period surrounding sterling's membership of the ERM. Prior to joining the ERM the nominal yield curve was downward sloping, but after sterling's exit it became upward sloping. This seems to suggest that the markets were expecting inflation to fall from its high value prior to joining the ERM, and to rise after leaving the ERM. As can be seen, in the event, the former did occur, but not the latter.

For most of the time the indexed yield curve is fairly flat. There are two episodes where it was not; it sloped upwards in 1987-88, and again immediately after leaving the ERM. The former was a period when the economy was expanding rapidly, and the latter was when it was coming out of recession. Two possible explanations for a rising indexed term structure are that either the markets thought real returns would rise in the future, or uncertainty about the future of the real economy is being reflected in higher real risk premia. Our estimates should throw more light on this.

The additional features revealed by the summary statistics relate to the persistence and stability of the yields. The first-order autocorrelation coefficients for the whole period show that there is considerable persistence for both indexed and nominal yields. The unit root tests indicate whereas the indexed yields are border-line stationary, the nominal yields are non-stationary. Of the two unit root tests reported the Phillips-Perron (1988) statistic $Z_{t \mu}(\mathrm{PP})$ is the more significant. It is also to be preferred as it allows both for a more general dynamic structure and conditional heteroskedasticity. The ADF test assumes an autocorrelation structure for the dynamics and homoskedasticity. The PP test is also more appropriate given our proposed use of a generalized CIR model and its implication of conditional heteroskedasticity. The main concem with the PP statistic is about the size of the test. 
These statistics show variation in the sub-samples, particularly the unit root test statistics which become more significant. Although the smaller number of observations in each sub-period make the tests more unreliable, such apparent structural instability is consistent with the existence of shifts in the monetary regime over the sample, and would justify splitting the sample into the different monetary regimes. In the event that the yields are non-stationary, it may be recalled that, unlike the CIR continuous time model, our model permits the factors to have a unit root.

\subsection{Estimates}

The Kalman filter estimates of the factor model are reported in Table 2 both for the whole sample and for the three sub-samples. First we consider the results for the whole sample, then we compare these with the sub-period results. The simplex method of MATLAB was used in the optimization. The persistence parameters $\phi_{1}$ and $\phi_{2}$ are constrained to lie between zero and unity, and the risk parameters $\lambda_{1}$ and $\lambda_{2}$ are constrained to be negative. In addition, we used penalty functions to keep the risk premia non-negative, the real risk premia smaller than indexed yields and the inflation risk premia smaller than the differentials between nominal and indexed yields. Numerical methods were used to compute the standard errors.

The estimates for the whole sample are similar to those for the first sub-period prior to sterling joining the ERM. There is more variation for the other two sub-samples. All of the full sample estimates for the inflation factor are highly significant. Even though some of the subsample estimates are not significant, they are so similar to the full sample estimates to suggest that their lack of significance is due to the smaller sample sizes. In general the parameter estimates of the real factor model are less well determined, but again the strong similarities in the different sub-samples suggests that this is more a matter of lack of estimation precision than doubt about the parameter values themselves. 
The full sample estimates imply a mean real return of $3.1 \%$ and average inflation of $4.7 \%$. These vary in each sub-sample, but for the whole period they imply means of $5.3 \%$ for inflation and $4.1 \%$ for real returns. The estimates of the other parameters are more similar for each sample. The persistence parameters, $\phi_{1}$ and $\phi_{2}$, imply that the real factor has a root close to unity but the inflation factor is much more stationary. This reverses the findings of Table 1 which show indexed yields to be more stationary that nominal yields. The estimates of $\sigma_{1}$ and $\sigma_{2}$ imply that the inflation factor is about ten times more volatile than the real factor for all sets of estinates. This pattern is reversed for the risk parameters $\lambda_{1}$ and $\lambda_{2}$, which show that the real risk is greater than the inflation risk parameter. ${ }^{7}$

A likelihood ratio test of no structural change gives a test statistic of 820 . On the null hypothesis of no structural change this is distributed as a Chi-squared with 32 degrees of freedom and is therefore highly significant. In view of this, in the rest of the paper the sub-sample results are combined to calculate the implied risk premia and expected inflation over the whole sample period.

Some idea of how well the combined models fit the data over the whole sample period can be obtained from Figures $2 \mathrm{a}-2 \mathrm{c}$ which plot actual and fitted for indexed and nominal yields for each maturity. The proportion of the variance of observed yields for the full data period that are explained by combining the sub-sample estimates is shown. The model fits nominal yields better than indexed yields. It is quite a demanding task for the model to fit all maturities for both nominal and indexed yields. In our view it does a reasonably good job, though there is obviously room for improvement, perhaps with factors related to the stance of monetary policy.

\footnotetext{
${ }^{7}$ It will be recalled, however, that due to our use of a generalized CIR model, these parameters are not strictly the correst measure of the price of risk.
} 


\subsubsection{Inflation and real risk premia}

The Kalman filter allows us to estimate the inflation and real risk premia for one period holding returns for all maturities for each month in the sample. From equations (10) and (18) the calculation requires us to back-out the factor values from the Kalman filter and to compute the factor loading coefficients for all maturities. The estimates of the two factors are shown in Figure 3 together with 2-year indexed yields and inflation for comparison. Clearly there is no close connection between the inflation and real factors and observed inflation and indexed yields.

Figure 4 shows the nominal and indexed yields and the estimated one period inflation, real and nominal risk premia for 2 -year yields. The smallness of the one period inflation risk premium probably reflects the lack of uncertainty about inflation over a one month horizon. Its mean value is 13 basis points. Even so it has been lower after leaving the ERM than before, suggesting that since then monetary policy has been more credible. The one period real risk premium is a larger with a mean of 141 basis points. Interestingly, it fell quite sharply immediately following entry to the ERM and again, though a little less sharply, on exit from the ERM. In partial response to the question raised earlier about the causes of the steep slope of the indexed yield curve during the period 1987-88 and in 1993, it may be observed that the one period real risk premium was relatively low in both periods.

The one-period risk premia will vary with the time to maturity and also with the value of the factors, see (10) and (18). The calculation above is based on a time to maturity of two years. Figure 5 shows how the risk premia vary with the time to maturity when the value of the factors are fixed at their whole period means. The inflation risk premium is large for bonds close to maturity, but is unaffected by the time to maturity when there is more than 6 months left. The real risk premium reaches its peak for maturities of about one year, dropping rapidly to zero both as the time maturity falls and increases. It is roughly constant for maturities greater than three years. 
The negative values of the real risk premium are an artifact of the use of factor means and can be ignored.

Estimates of the inflation and real risk premia for 2-year bonds (i.e. their average expected values over the rest of the life of the bonds) together with the nominal and indexed yields are shown in Figure 6. The average value of the inflation risk premium is 107 basis points, while that for the real risk premium is 272 basis points. Put another way, the inflation risk premium accounts for about $1 \%$ of the nominal yield, and the real risk premium accounts for another $2.7 \%$. These are larger values than the one-period risk premia for 2-year bonds due to the fact that the two one-period risk premia increase in size towards the end of the life of the bonds, as shown in Figure 5.

It appears that entry into the ERM had a much bigger impact on the inflation and real risk premia than exit. The inflation risk premium fell on entry to the ERM by about 50 basis points and thereafter stayed at about 70 basis points. This shows the increased credibility of monetary policy since entry to the ERM, and that this has not been affected by the exit. If anything, there has been a slight improvement in recent years. The real risk premium fell by nearly 175 basis points on entry to the ERM, and then fluctuated between 170 and 260 basis points thereafter reflecting uncertainty about the real economy.

\subsubsection{Inflation expectations}

The inflation expectations embedded in the term structure -- the expected average rate of inflation over the remaining life of an $n$-period bond -- can be calculated in two ways, depending on whether observed yields are used in equation (21), or whether yields are estimated from the affine factor pricing equations (7) and (16). Only the second method is available for maturities for which there are no observations. In either case it is first necessary to estimate the inflation 
risk premium for $n$-period nominal yields. Corresponding estimates can be obtained of the expected average real return.

Figure 7 shows expected average inflation over the next two years estimated using the break-even method (the difference between the nominal and indexed yields of matching zerocoupon bonds) and our proposed adjustment to this for the inflation risk premium. It is clear that the unadjusted break-even method will always provide a higher inflation estimate -- by about $1 \%$. Although estimated average inflation over the next two years follows a similar path to the actual average, it does so with a pronounced lag. A regression (not reported) of estimated average inflation over the next two years on a distributed lag of actual average shows that this lag is eight months. It is clear that the cause of this is the eight month indexation lag. In other words, the adjusted difference in the yields provides information on average inflation for the two-year period starting eight months earlier, (i.e. from $t-8$ to $t+16$ ).

It is also of interest to know whether or not the adjusted yield difference provides an unbiased estimate of average inflation over this two-year period. This can tested from the model

$$
\pi_{24, t-8}=\alpha+\beta \pi_{24, \imath}^{I}+\xi_{t} \quad \mathrm{I}=\mathrm{A}, \mathrm{U}
$$

where $\pi_{24, t-8}$ is actual average inflation over the two-year period starting in $t-8, \pi_{24, t}^{I}$ is the estimate of adjusted (A) or unadjusted (U) average future inflation over the next two years for $\{\mathrm{I}=\mathrm{A}, \mathrm{U}\}$ and $\xi_{t}$ is an error term. If the estimate of inflation is unbiased then $\alpha=0$ and $\beta=1$. OLS estimates of equation (29) for the two measures of expected inflation are reported in Table 3. As both sets of estimates have highly serially correlated disturbances due to the dependent variable being a two-year average, Newey-West standard errors corrected for serial correlation are reported. At first sight the two sets of estimates appear to be similar since the unbiasedness hypothesis cannot be rejected and they have nearly identical slope coefficients. The 
main difference is in the estimate of the intercept. Although neither of the intercepts is significantly different from zero, the point estimate of the intercept for the adjusted inflation equation is much closer to zero than for the unadjusted equation. In fact the difference between the intercepts almost exactly matches the average value of the adjustment for the inflation risk premium. This provides a powerful reason for making the adjustment.

It was pointed out earlier that the affine pricing models allow us to estimate inflation expectations over any time horizon, and not just those for which we have observed yields - or have used the observed yields in the estimation. In practice, however, it might be best to use the yields corresponding to the desired inflation in the estimation. To illustrate this, in Fig. 8 we show the predictions of inflation one year ahead implied by our model estimates. This involves first predicting the difference in one-year nominal and indexed yields, and then adjusting this by the one-year inflation risk premium. The average one-year-ahead inflation risk premium is 98 basis points, similar to the 107 basis points for two-year-ahead inflation.

\subsubsection{The slopes of the nominal and indexed yield curves reinterpreted}

It was noted earlier that prior to joining the ERM the nominal yield curve sloped downwards, and that since exit it has sloped upwards. One explanation for this is that it reflects inflation expectations. This is consistent with the fall in inflation after entry into the ERM, but there has been no corresponding increase in inflation following exit. A full explanation for the slopes also requires the risk premia to be taken into account. Our estimates show that prior to entry the nominal risk premium was at its highest, but that it fell by 225 basis points on entry to the ERM, and this affected all yields. This suggests that the risk premia have also made a contribution to the change in slope.

The upward sloping yield curve after exit is less easy to explain. Not only has inflation not increased, the inflation risk premium has stayed constant. Only the real risk premium has 
shown any movement. It may also be noted that the periods when the real risk premium has been highest correspond to those when the indexed yield curve is at its steepest as in 1993 . The implication is that the upward sloping yield curve since 1992 is due largely to perceptions of real risk.

\section{Conclusions}

In this paper we have attempted to show how the inflation and real risk premia embodied in the nominal term structure can be estimated by combining the information in the nominal term structure with that in the indexed-linked term structure. We have used a generalised CIR affine factor pricing model, estimated by the Kalman filter. Our results suggest that a two-factor model is the bare minimum needed. The model seems to exhibit structural change during the sample period from 1982 to 1997 . This is probably due to the changes in monetary regime associated with ERM entry and exit. We have therefore divided the full sample into three sub-samples and then re-combined the estimates to produce measures of the risk premia and the inflation forecasts over the whole period.

Arguably, the inflation risk premium is both a measure of the cost of issuing nominal rather than indexed-linked debt, and of the credibility of monetary policy, while the real risk premium is a measure of uncertainty about the real economy. Our results suggest that the inflation risk premium contributes on average about $1 \%$ of the nominal yield on two year bonds, and represents the cost of issuing nominal rather than indexed-linked debt. Since leaving the ERM this has fallen to about 70 basis points. This indicates that the credibility of monetary policy has improved since entry to the ERM, and was not harmed by leaving the ERM. These movements in the inflation risk premium are consistent with the evidence about the expected future direction of inflation implied by the slope of the nominal yield curve. A high inflation risk 
premium is accompanied by a downward sloping yield curve at the medium to long end, implying that inflation is expected be higher in the short than the medium term. Since leaving the ERM this has been exactly reversed. This indicates that inflation risk is largely due to short-run factors, something confirmed by our estimates of the term structure of the inflation risk premium.

We estimate that the real risk premium since leaving the ERM has been about $2.5 \%$, but has fluctuated between 170 and 260 basis points, reflecting uncertainty about the recovery and its sustainability. The periods when the real risk premium has been highest correspond to when the indexed yield curve is at its steepest.

We have shown how the inflation risk premium can be used to derive a correction to the break-even method of forecasting future inflation. Once allowance is made for the eight-month indexation lag, the adjusted forecast provides an unbiased estimate of future inflation. 


\section{References}

Ait-Sahalia, Y., 1996. Testing continuous-time models of the spot interest rate. Review of Financial Studies 9, 427-470.

Arak, M., Kreicher, L., 1985. The real rate of interest: Inferences from the new UK index-linked gilts. International Economic Review 26, 399-408.

Backus, D., Zin, S., 1993. Long-memory inflation uncertainty: Evidence from the term structure. Journal of Money, Credit, and Banking 25, No. 3, Part 2 (August), 681-708.

Backus, D., Zin, S., 1994. Reverse engineering the yield curve. Unpublished working paper. New York University.

Barr, D.G., Campbell, J.Y., 1997. Inflation, real interest rates, and the bond market: A study of UK nominal and index-linked government bond prices. Journal of Monetary Economics 39, 361384.

Brown, R.H., Schaefer, S.M., 1994. The term structure of real interest rates and the Cox, Ingersoll, and Ross model. Journal of Financial Economics 35, 3-42.

Brown, R.H., Schaefer, S.M., 1996. Ten years of the real term structure 1984-1994. Journal of Fixed Income 5, 6-22.

Campbell, J., A. Lo, A., MacKinlay, C., 1997. The Econometrics of Financial Markets. Princeton University Press, Princeton.

Chen, R.-F., Scott, L., 1993. Maximum likelihood estimation for a multifactorequilibrium model of the term structure of interest rates. Joumal of Fixed-Income (December) 14-31.

Cox, J., Ingersoll, J., Ross, S., 1985. A theory of the term structure of interest rates. Econometrica $53,385-408$. 
Dai, Q., Singleton, K., 1998. Specification analysis of affine term structure models. Unpublished working paper. Stanford University (January).

Deacon, M., Derry, A.J., 1994. Deriving estimates of inflation expectations from the prices of UK government bonds. Bank of England Working Paper 23.

Duffie, D., Kan, R., 1996. A yield-factor model of interest rates. Mathematical Finance 6, 379406.

Engle, R.F., Lilien, D.M., Robins, R.P., 1987. Estimating time varying risk premia in the term structure: The ARCH-M model. Econometrica 55, 391-407.

Engsted, T., 1995. Does the long-term interest rate predict future inflation? A multi-country analysis. Review of Economics and Statistics, 42-54.

Evans, M.D.D., 1998. Real rates, expected inflation, and inflation risk premia. Journal of Finance $53,187-218$.

Fama, E.F., 1984. The information in the term structure. Journal of Financial Economics 13, 509528.

Fama, E.F., 1990. Term structure forecasts of interest rates, inflation, and real returns. Joumal of Monetary Economics 25, 59-76.

Frankel, J., Lown, C., 1994. An indicator of future inflation extracted from the steepness of the interest rate yield curve along its entire length. Quarterly Joumal of Economics (May) 517-530.

Gong, F., Remolona, E., 1997. Two factors along the yield curve. Papers in Money,

Macroeconomics and Finance: The Manchester School Supplement 65, 1-31.

Jegadeesh, N., Pennacchi, G., 1996. The behavior of interest rates implied by the term structure of Eurodollar futures. Joumal of Money, Credit, and Banking. 
Keim, D.B., Stambaugh, R.F., 1986. Predicting returns in the stock and bond markets. Journal of Financial Economics 17, 357-390.

King, M., 1995. Credibility and monetary policy: Theory and evidence. Scottish Journal of Political Economy 42, 1-19.

Levin, E.J., Copland, L.S., 1993. Reading the message from the U.K. indexed bond market: Real interest rates, expected inflation, and the risk premium. The Manchester School 61, 13-34.

Longstaff, F.A., Schwartz, E.S., 1992. Interest rate volatility and the term structure: A two-factor general equilibrium model. Journal of Finance 47, 1259-82.

Mishkin, F., 1990. What does the term structure tell us about future inflation? Journal of Monetary Economics 25, 77-95.

Pearson, N.D., Sun, T.S., 1994. Exploiting the conditional density in estimating the term structure: An application to the Cox, Ingersoll, and Ross model. Journal of Finance 49, 1279 1304.

Pennacchi, G., 1991. Identifying the dynamics of real interest rates and inflation: Evidence using survey data. Review of Financial Studies 4, 53-86.

Phillips, P.C.B., Perron, P., 1988. Testing for a unit root in time series regression. Biometrika 75, 335-346.

Singleton, K.J., 1990. Specification and estimation of intertemporal asset pricing models. In:

Friedman, B. and Hahn, F. (Eds.), Handbook of Monetary Economics. North Holland, Amsterdarn.

Steeley, J., 1997. A two-factor model of the U.K. yield curve. Papers in Money. Macroeconomics and Finance: The Manchester School Supplement 65, 32-58. 
Sun, T.-S., 1992. Real and nominal interest rates: A discrete-time model and its continuous-time limit. Review of Financial Studies 5, 581-611.

Shiller, R.J., Campbell, J.Y., Schoenholtz, K.L., 1983. Forward rates and future policy:

Interpreting the term structure of interest rates. Brookings Papers on Economic Activity 1, $173-$

217.

Tzavalis, E., Wickens, M.R., 1996. Forecasting inflation from the term stnucture. Journal of Empirical Finance 3, 103-122.

Tzavalis, E., Wickens, M.R., 1997. Explaining the failures of the term spread models of the rational expectations hypothesis of the term Structure. Journal of Money, Credit and Banking 29. $364-380$.

Tzavalis, E., Wickens, M.R., 1998. A reexamination of the rational expectations hypothesis of the term structure: Reconciling the evidence from long-run and short-run tests. Intermational Journal of Finance and Economics, forthcoming.

Vasicek, O.A., 1977. An equilibrium characterization of the term structure. Journal of Financial Economics 5, 177-188.

Wong, F., 1964. The construction of a class of stationary Markov processes. In: Bellman, R.

(Ed.), Stochastic Processes in Mathematical Physics and Engineering, Proceedings of Symposia in Applied Mathematics, 16, American Mathematical Society, Providence, R.I., 264-276. 
Table 1.

Summary Statistics

2,5 and 10 year index and nominal yields

\begin{tabular}{|c|c|c|c|c|c|}
\hline Variable & Mean \% & $\begin{array}{c}\text { Standard } \\
\text { Deviation \% }\end{array}$ & $\begin{array}{l}\text { First Order Auto- } \\
\text { correlation }\end{array}$ & $\overline{A D F(12)}$ & PP \\
\hline & & $83.1-97.7$ & & & \\
\hline $2 y r$ index & 3.35 & 0.98 & 0.85 & -2.95 & -3.47 \\
\hline $5 y r$ index & 3.59 & 0.55 & 0.84 & -3.46 & -5.09 \\
\hline $10 \mathrm{yr}$ index & 3.67 & 0.40 & 0.84 & -3.74 & -6.11 \\
\hline $2 y r$ nominal & 9.12 & 2.06 & 0.96 & -1.66 & -3.01 \\
\hline 5yr nominal & 9.35 & 1.68 & 0.95 & -1.34 & -3.11 \\
\hline $10 y r$ nominal & 9.39 & $\begin{array}{c}1.35 \\
83.1-90.9\end{array}$ & 0.94 & -1.56 & -2.83 \\
\hline 2yr index & 3.39 & 1.20 & 0.87 & -2.00 & -2.66 \\
\hline $5 y r$ index & 3.61 & 0.61 & 0.82 & -2.27 & -4.20 \\
\hline 10yr index & 3.62 & 0.39 & 0.76 & -2.89 & -5.19 \\
\hline $2 y r$ nominal & 10.49 & 1.26 & 0.88 & -1.00 & -4.51 \\
\hline $5 y r$ nominal & 10.47 & 1.06 & 0.87 & -1.13 & -4.00 \\
\hline 10yr nominal & 10.28 & $\begin{array}{c}0.92 \\
90.10-92.8\end{array}$ & 0.86 & -1.64 & -3.07 \\
\hline $2 y r$ index. & 3.65 & 0.21 & 0.52 & -1.69 & -1.34 \\
\hline $5 y r$ index & 4.03 & 0.50 & 0.57 & 0.79 & -1.78 \\
\hline $10 \mathrm{yr}$ index & 4.20 & 0.84 & 0.61 & 1.02 & -2.27 \\
\hline $2 y r$ nominal & 9.94 & 0.64 & 0.69 & -3.96 & -0.07 \\
\hline 5yr nominal & 9.80 & 0.34 & 0.72 & -2.06 & -0.28 \\
\hline 10yr nominal & 9.67 & $\begin{array}{c}0.23 \\
92.8-97.7\end{array}$ & 0.75 & -1.00 & -0.97 \\
\hline $2 y r$ index & 3.17 & 0.66 & 0.83 & -2.94 & -1.58 \\
\hline $5 y r$ index & 3.40 & 0.42 & 0.85 & -4.05 & -1.60 \\
\hline $10 y r$ index & 3.54 & 0.30 & 0.83 & -4.67 & -1.58 \\
\hline 2yr nominal & 6.64 & 0.77 & 0.87 & -6.61 & -1.79 \\
\hline $5 y r$ nominal & 7.40 & 0.75 & 0.88 & -4.46 & -1.85 \\
\hline 10yr nominal & 7.87 & 0.62 & 0.82 & -2.73 & -1.92 \\
\hline
\end{tabular}

Note: the $5 \%$ critical values for 25 and 100 observations are

1. ADF test: $-3.95(25)$ and $-3.45(100)$

2. PP $\left(Z_{t \mu}\right)$ test: $-3.00(25)$ and $-2.89(100)$ 
Table 2

A Two-Factor Model of the U.K. Term Structure

Parameters (standard errors)

\begin{tabular}{|c|c|c|c|c|}
\hline Sarnple period & $\begin{array}{l}\text { Full sample } \\
1982: 7-97: 7\end{array}$ & $\begin{array}{l}\text { Pre-ERM } \\
\text { 1982:7-90:9 }\end{array}$ & $\begin{array}{l}\text { ERM period } \\
\text { 1990:10-92:8 }\end{array}$ & $\begin{array}{l}\text { Post-ERM } \\
1990: 9-97: 7\end{array}$ \\
\hline \multicolumn{5}{|l|}{ Inflation factor } \\
\hline Mean & $17.021(3.15)$ & $20.921 \quad(1.72)$ & $13.560(6.54)$ & $10.763(1.18)$ \\
\hline Persistence & $0.797(0.01)$ & $0.797 \quad(0.01)$ & $0.750 \quad(0.16)$ & $0.752(0.01)$ \\
\hline Price of risk & $-1.061(0.30)$ & $-1.061 \quad(0.35)$ & $-1.063(0.44)$ & $-1.061 \quad(0.74)$ \\
\hline Beta & $0.230(0.02)$ & $0.229 \quad(0.02)$ & $0.246(0.06)$ & $0.248 \quad(0.04)$ \\
\hline Volatility & $2.113(0.06)$ & $2.116 \quad(0.02)$ & $1.852(0.99)$ & $1.857(0.05)$ \\
\hline \multicolumn{5}{|l|}{ Real factor } \\
\hline Mean & $10.453(13.32)$ & $11.164(12.80)$ & $8.045(16.16)$ & $7.722 \quad(5.69)$ \\
\hline Persistence & $0.968 \quad(0.02)$ & $0.970 \quad(0.02)$ & $0.960(0.04)$ & $0.964(0.01)$ \\
\hline Price of risk & $-7.880 \quad(1.34)$ & $-7.883 \quad(5.62)$ & $-8.411(6.80)$ & $-8.573(1.71)$ \\
\hline Beta & $0.368 \quad(0.86)$ & $0.368 \quad(0.95)$ & $0.368 \quad(0.72)$ & $0.368 \quad(0.91)$ \\
\hline Volatility & $0.222 \quad(0.71)$ & $0.227(1.03)$ & $0.176(0.60)$ & $0.181 \quad(0.55)$ \\
\hline \multicolumn{5}{|l|}{ Measurement error } \\
\hline 2-year index linked & 0.506 & 0.477 & 0.339 & 0.257 \\
\hline 5-year index linked & 0.245 & 0.281 & 0.129 & 0.174 \\
\hline 10-year index linked & 0.298 & 0.317 & 0.110 & 0.183 \\
\hline 2-year nominal & 0.366 & 0.328 & 0.002 & 0.000 \\
\hline 5-year nominal & 1.058 & 0.670 & 0.382 & 0.530 \\
\hline 10-year nominal & 1.298 & 0.861 & 0.495 & 0.815 \\
\hline Log likelihood & -563.63 & -210.37 & 43.35 & 13.29 \\
\hline
\end{tabular}


Table 3

Unbiasedness tests

\begin{tabular}{ccc}
\hline & unadjusted & adjusted \\
\hline$\alpha$ & -0.684 & -0.029 \\
$\beta$ & $(0.726)$ & $(0.632)$ \\
& 0.971 & 0.975 \\
$R^{2}$ & $(0.149)$ & $(0.151)$ \\
s.e. & 0.698 & 0.692 \\
DW & 1.122 & 1.124 \\
LM(12) & 0.267 & 0.266 \\
& 110.4 & 107.7 \\
& {$[0.000]$} & {$[0.000]$} \\
\hline
\end{tabular}

Notes:

(i) model: $\pi_{24, t-8}=\alpha+\beta \pi_{24, t}^{I}+\xi_{t} \quad\{\mathrm{I}=\mathrm{A}, \mathrm{U}\}$

(ii) Newey-West corrected standard errors in parentheses based on lag 24 and Parzen weights

(iii) p-values in square brackets

(iv) $\mathrm{LM}(12)$ is a chi-squared test for $12^{\text {th }}$ order serial correlation 

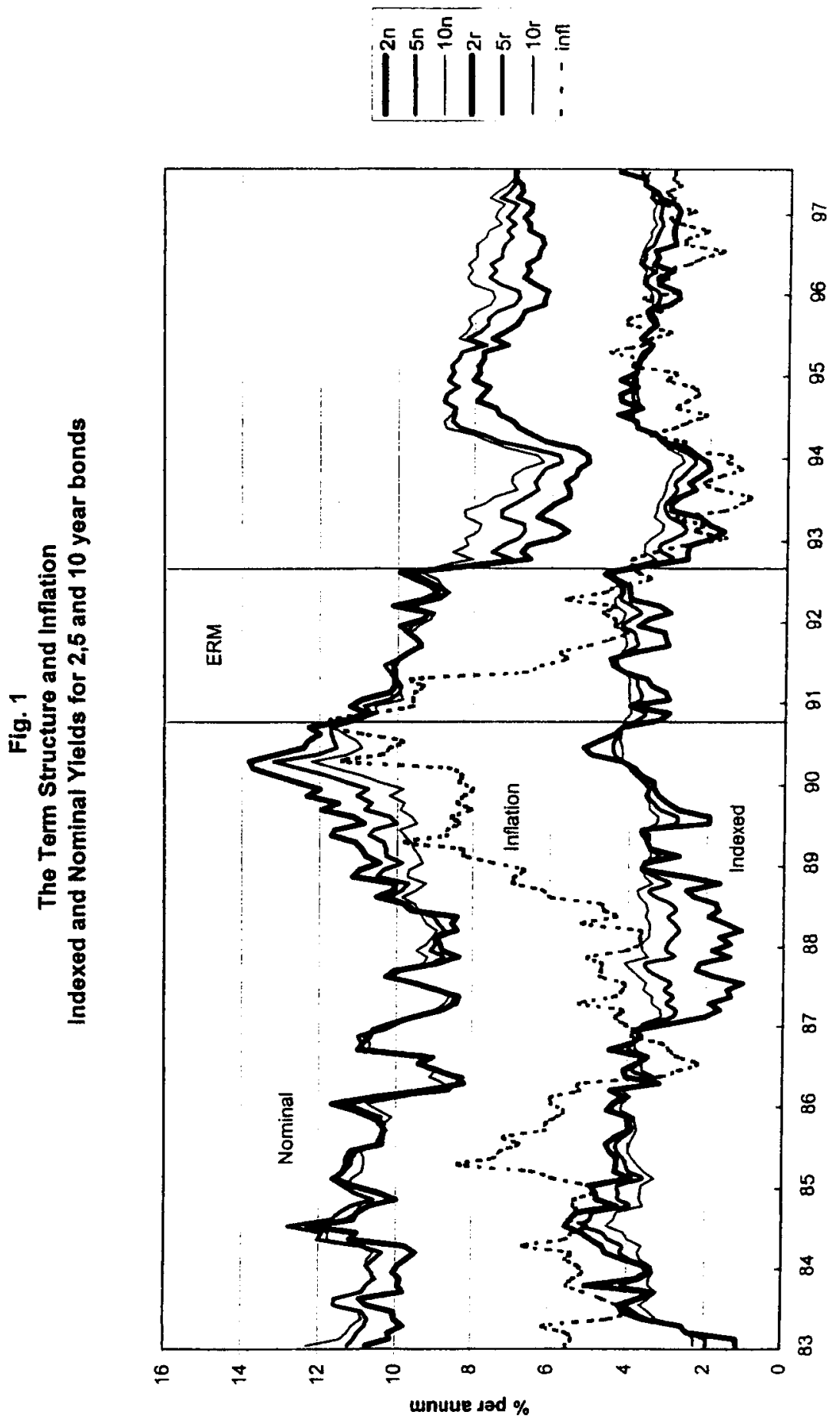


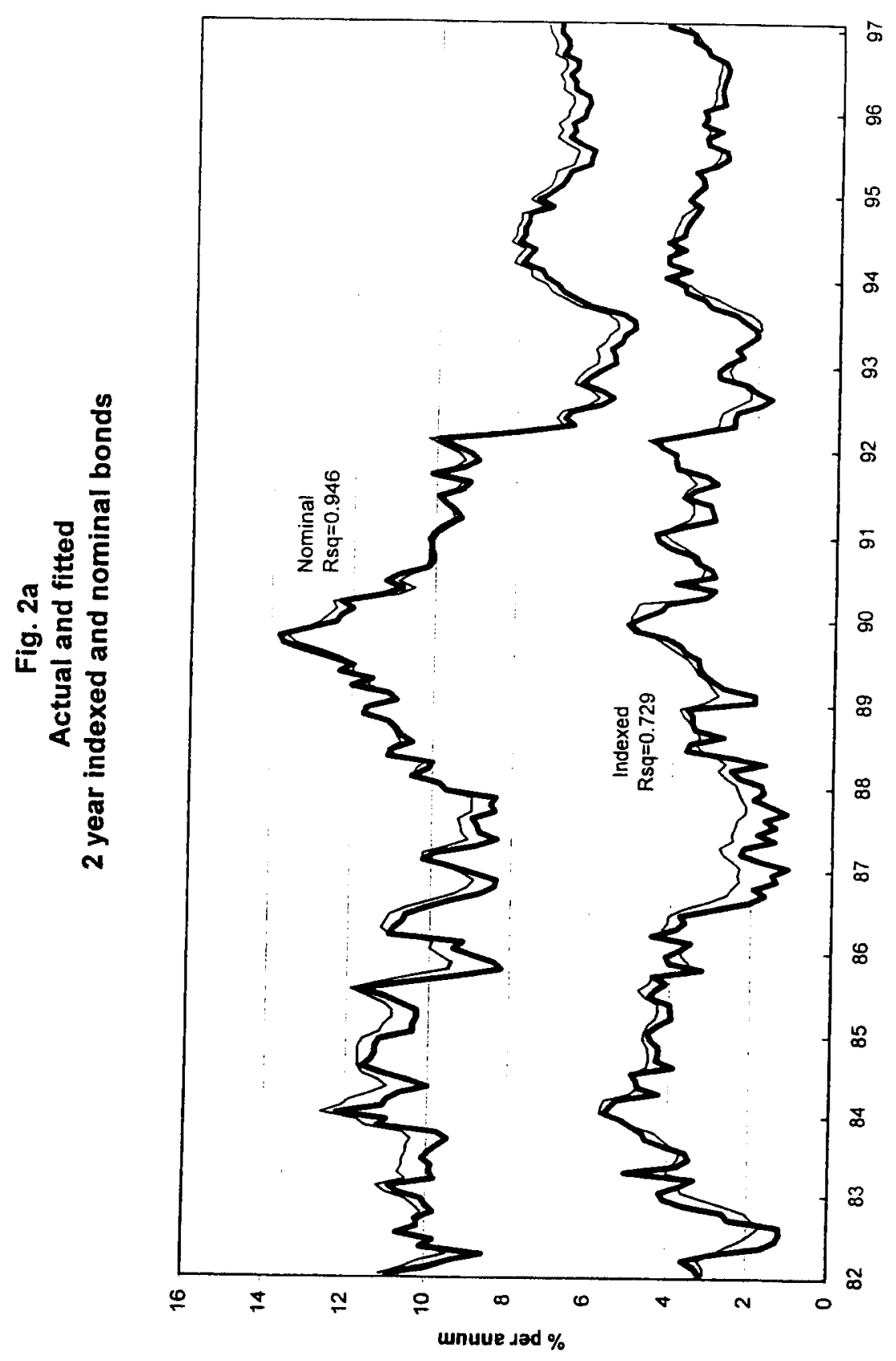




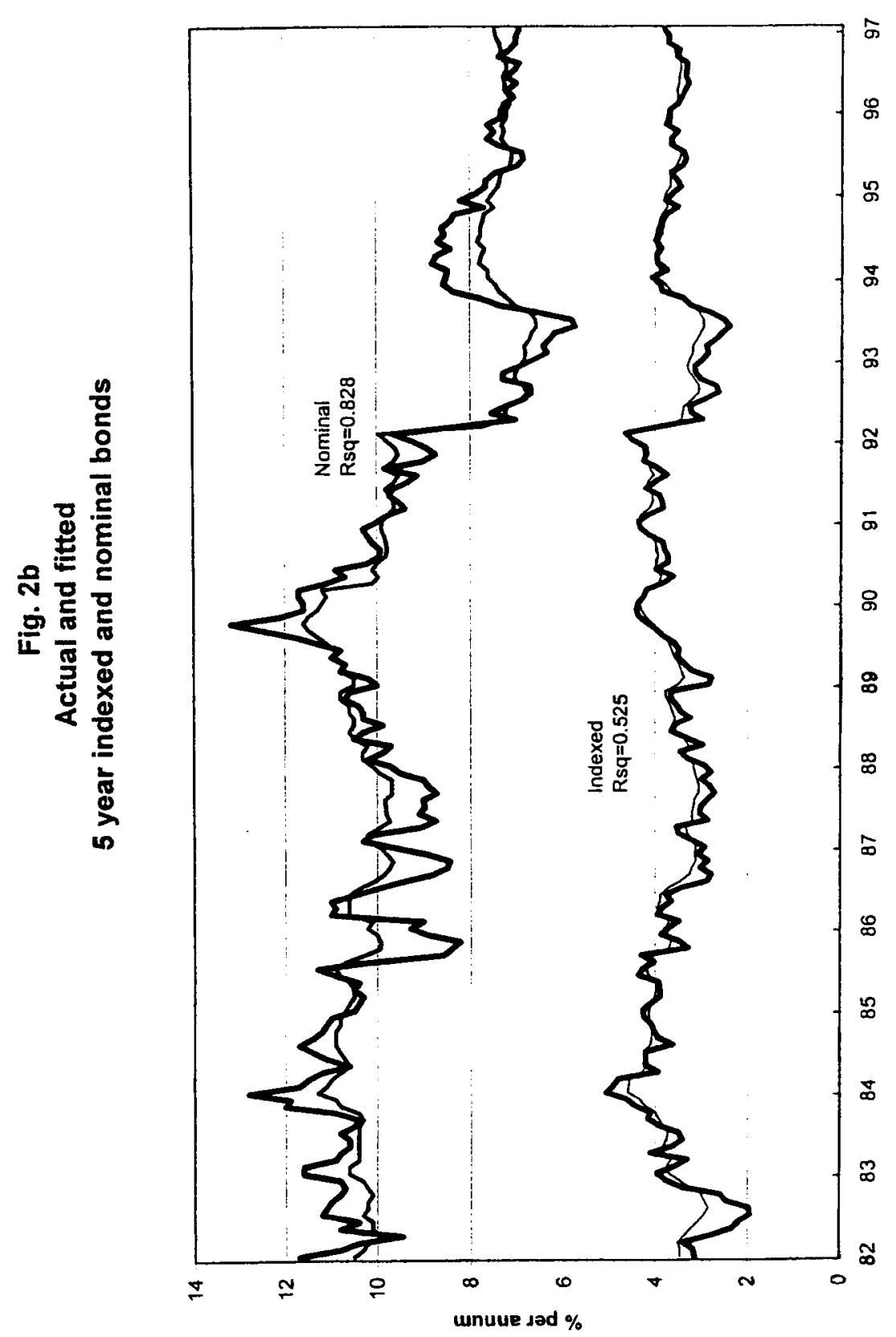




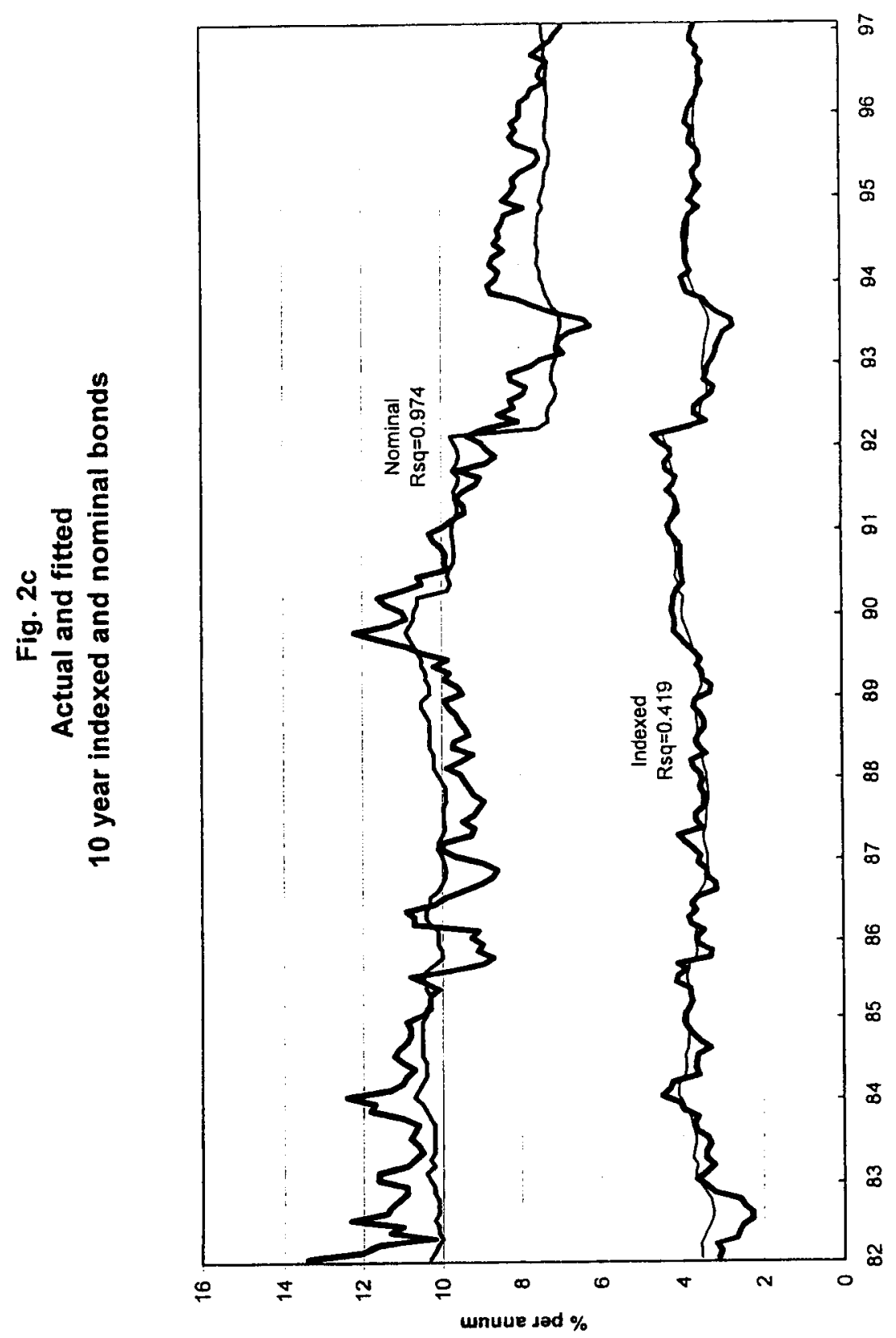




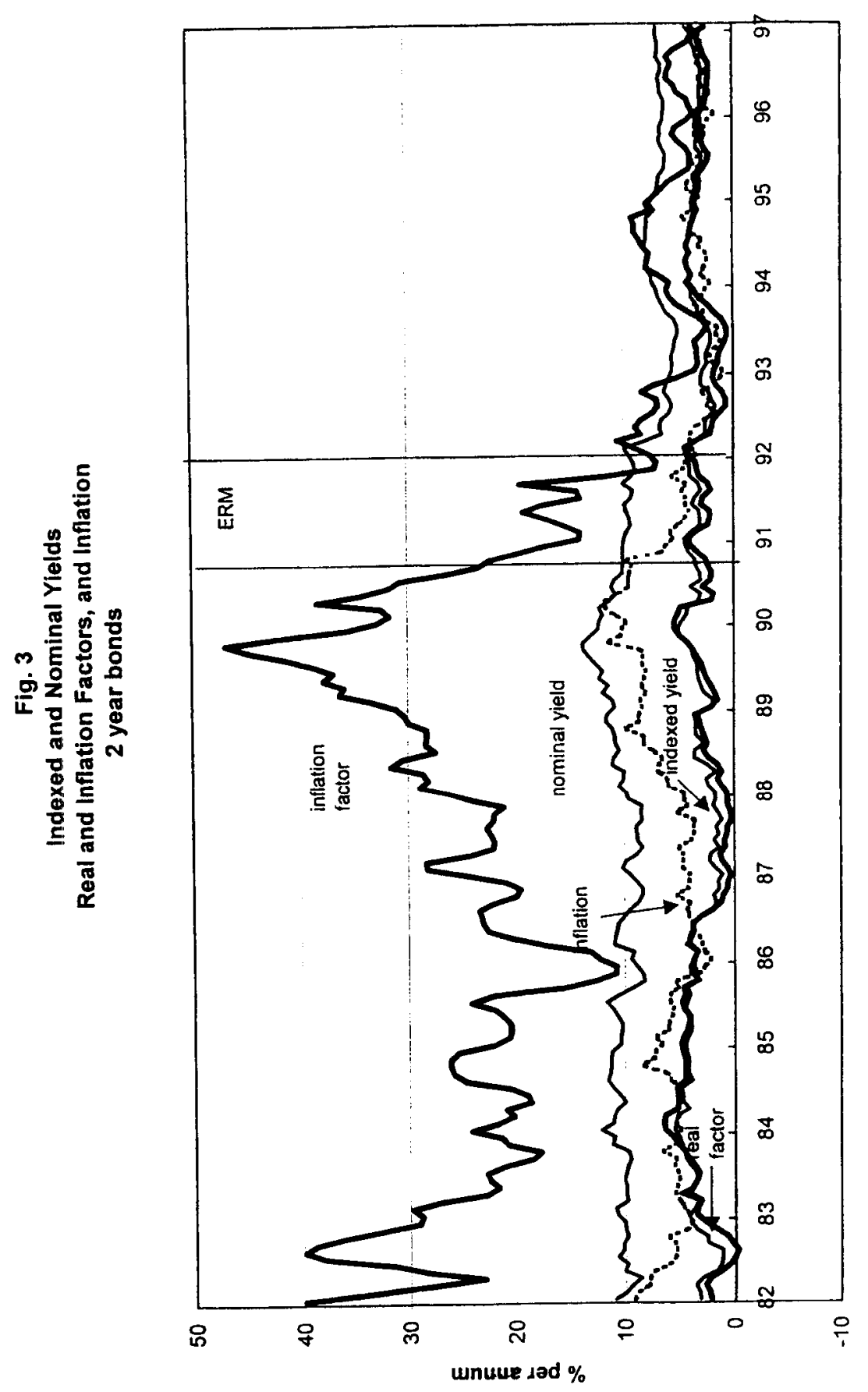




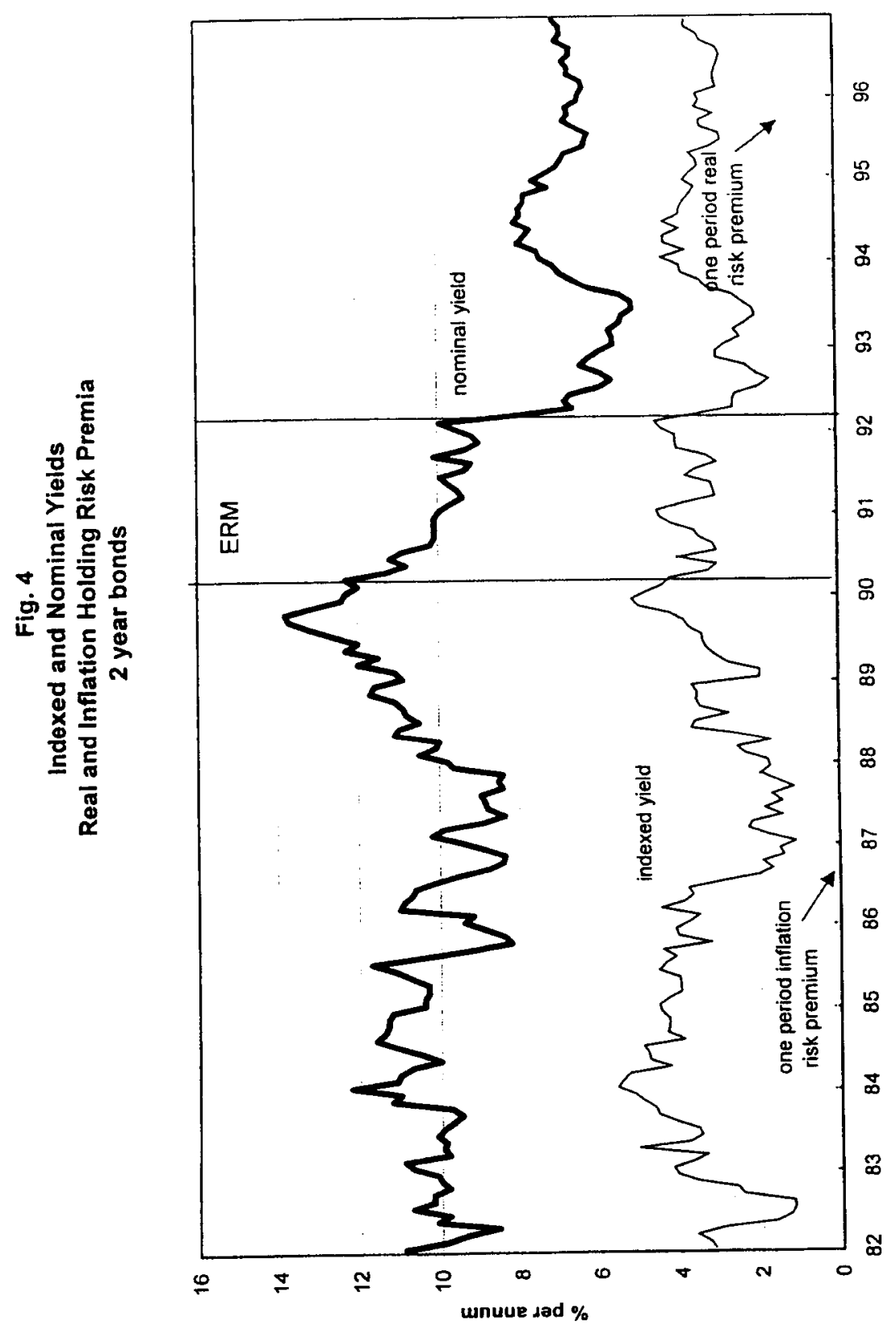




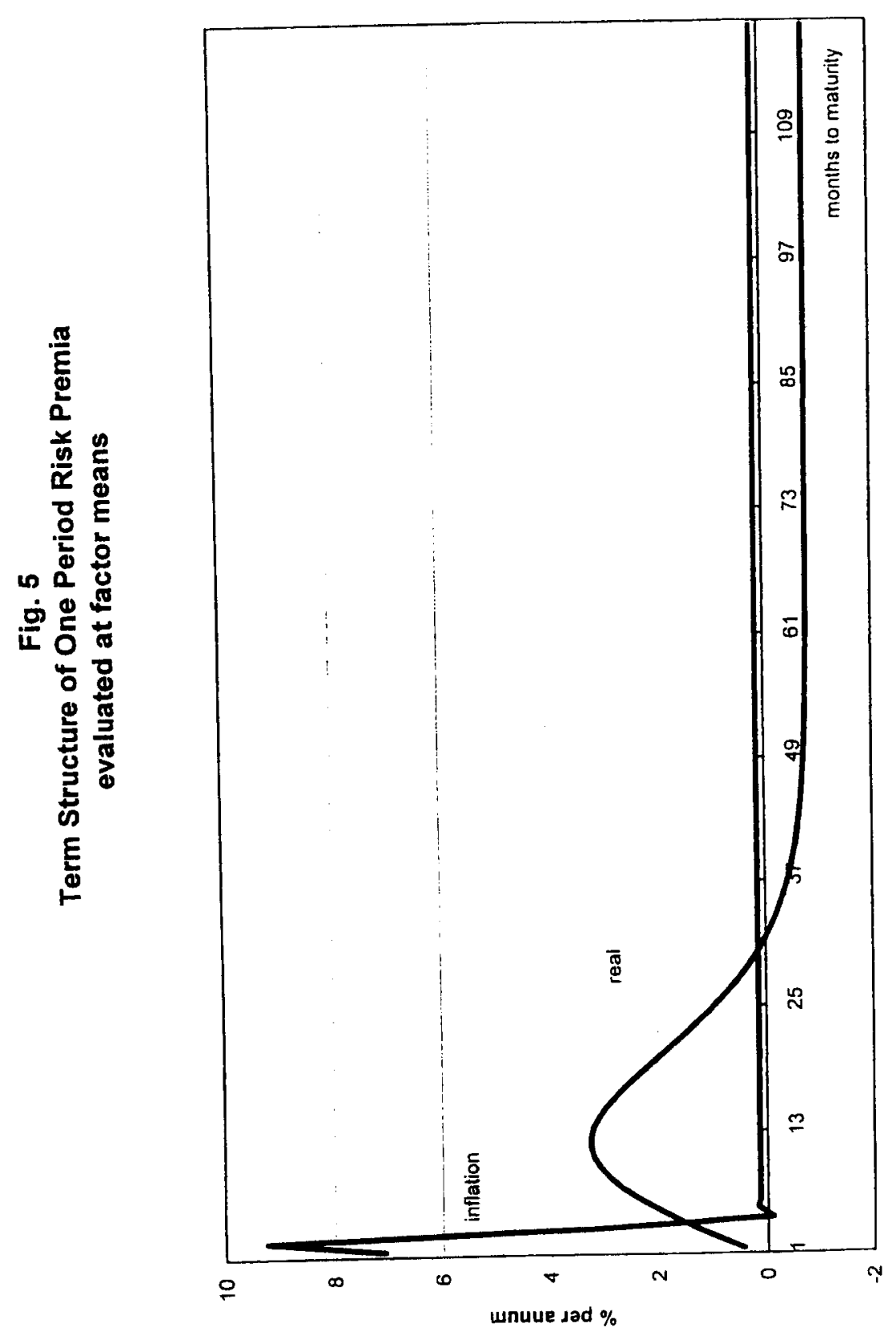




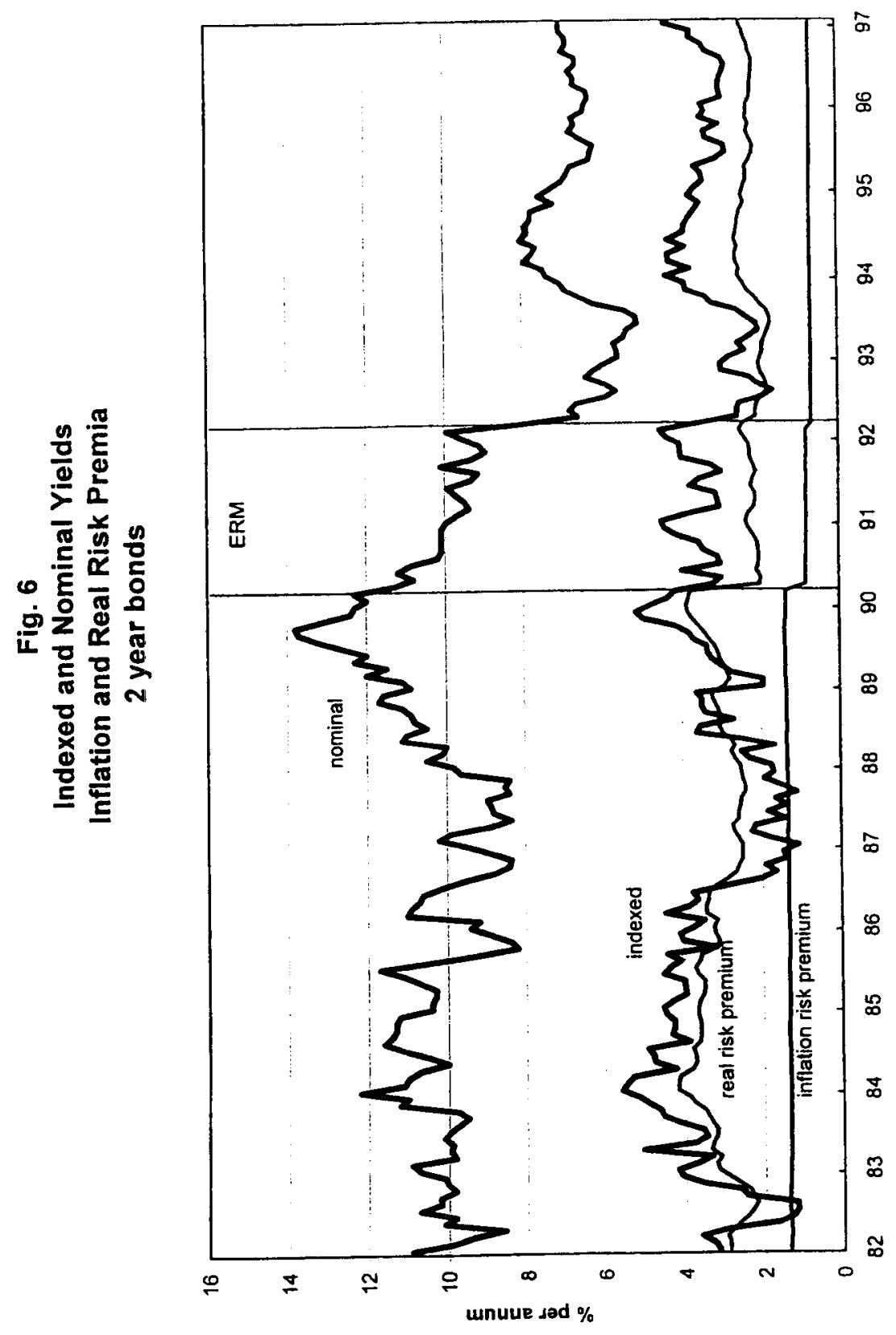




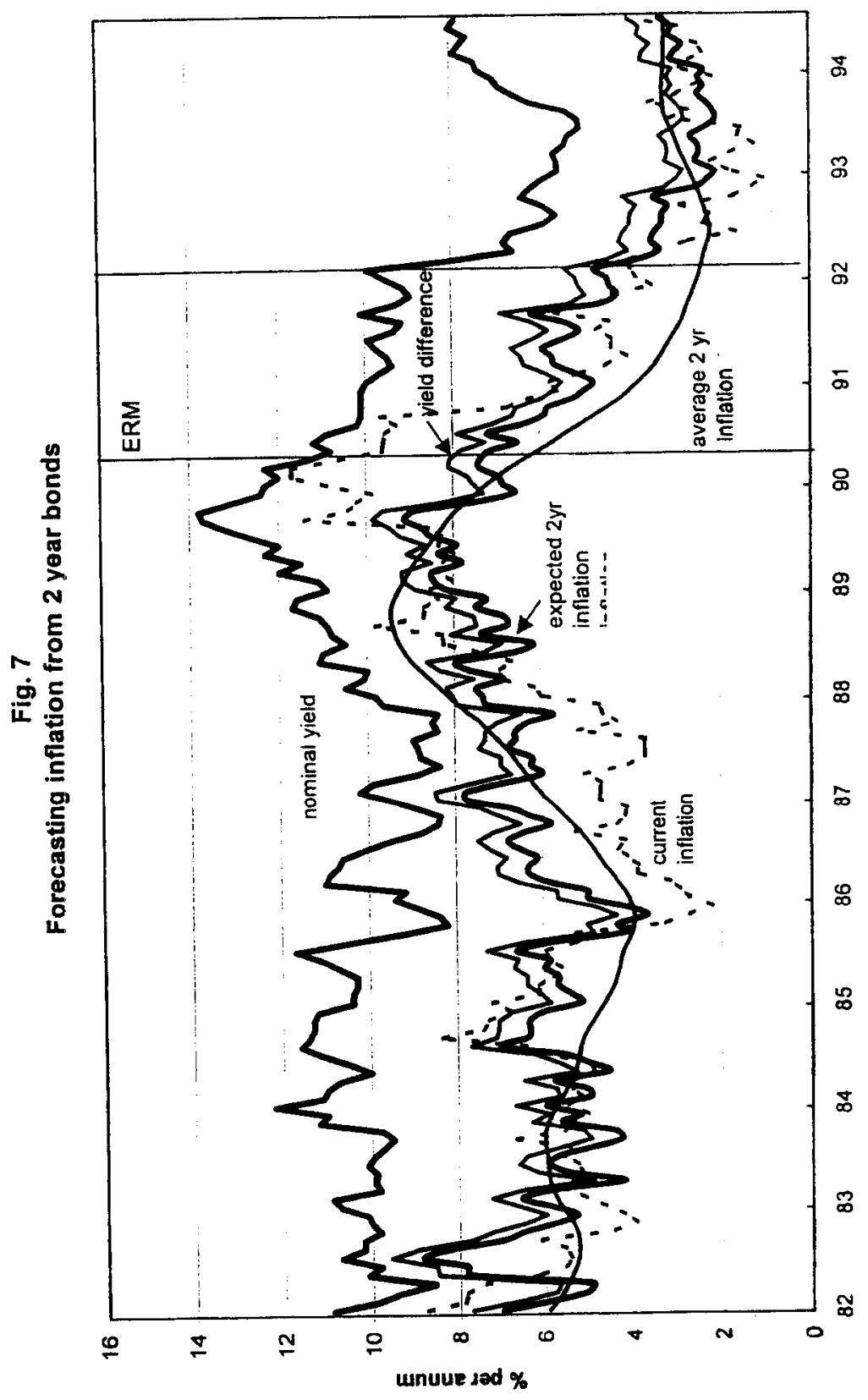




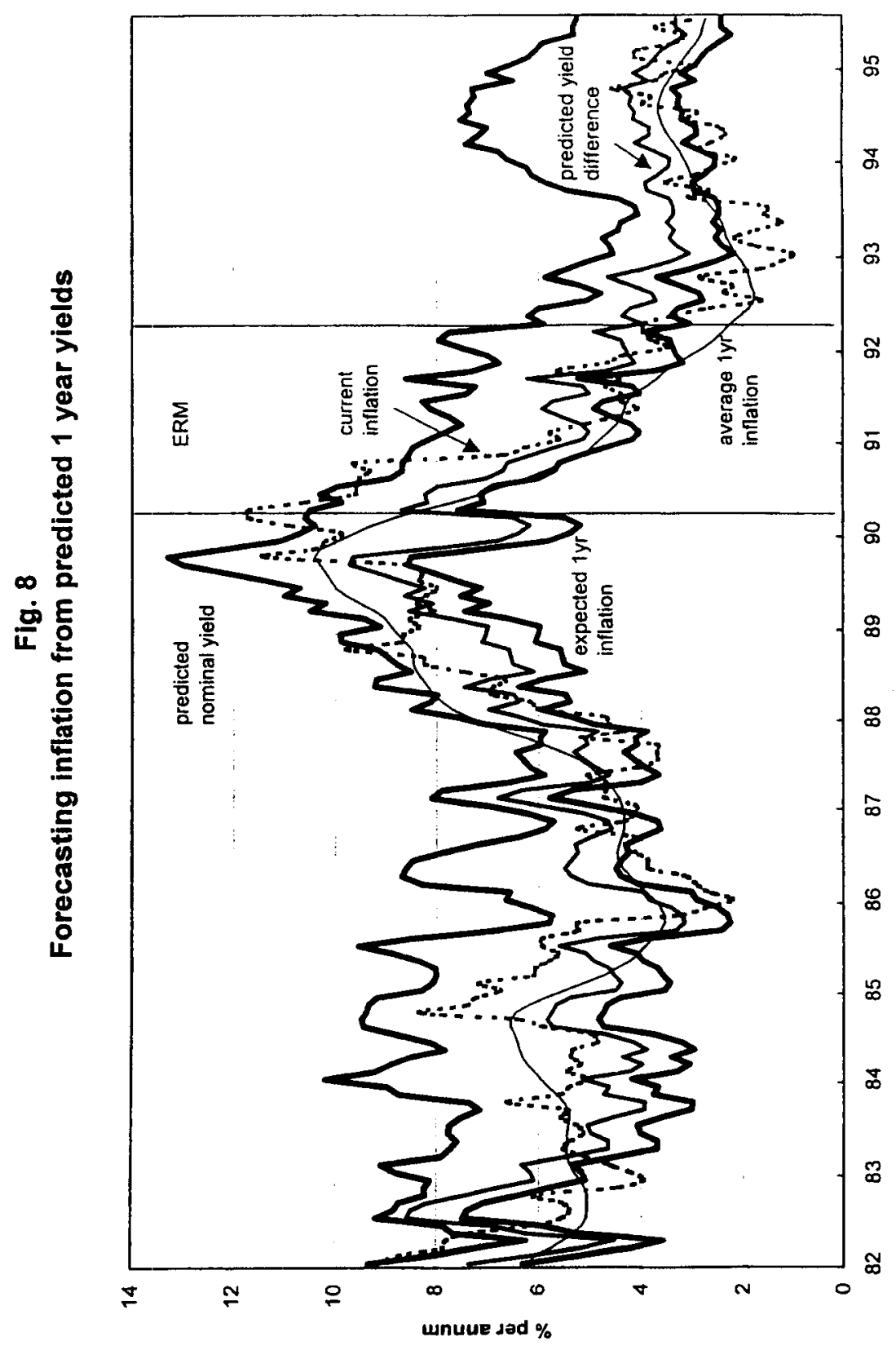

